\title{
Comprehensive assessment of radiation dose in patients undergoing percutaneous coronary intervention: the effect of beam angulation on patient dose optimization
}

\section{Z. Sancholi1,2, P. Hejazi3, A. Maziar1,2, R. Eskandarian4, R. Ghorbani5, M. Arabyarmohammadi ${ }^{6}$, R. Paydar ${ }^{1,2^{*}}$}

\author{
${ }^{1}$ Radiation Biology Research Center, Iran University of Medical Science (IUMS), Tehran, Iran \\ ${ }^{2}$ Radiation Science Department, Iran University of Medical Science (IUMS), Tehran, Iran \\ ${ }^{3}$ Department of Medical Physics, Faculty of medicine, Semnan University of Medical Sciences, Semnan, Iran \\ ${ }^{4}$ Department of Cardiology, Faculty of Medicine, Semnan University of Medical Sciences, Semnan, Iran \\ ${ }^{5}$ Social Determinants of Health Research Center, Semnan University of Medical Sciences, Semnan, Iran \\ ${ }^{6}$ Nuclear Engineering Department, Islamic Azad University, Sciences and Research branch, Tehran, Iran
}

\section{- Original article}

\section{*Corresponding author: \\ Reza Paydar, PhD., \\ E-mail: paydar.r@iums.ac.ir}

Revised: May 2020

Accepted: June 2020

Int. J. Radiat. Res., April 2021;

19(2): 381-390

DOI: $10.29252 /$ ijrr.19.2.371

\begin{abstract}
Background: Interventional cardiology (IC) procedures such as percutaneous coronary intervention $(\mathrm{PCl})$ could generate a high radiation dose to both patients and medical staff. In this study, a comprehensive analysis was performed on patient dose during $\mathrm{PCl}$ procedures and evaluating the effect beam angulation on dose-area product (DAP) rate in cardiac catheterization laboratory. Materials and Methods: We studied $30 \mathrm{PCl}$ procedures in angiography department during four months. A calibrated DAP meter was used to record patients' dosimetric characteristics. Effective dose (ED) was calculated using DAP values along with DAP to ED conversion factor. Local diagnostic reference levels (DRLS) of the DAP, fluoroscopy time, and number of CINE frames were calculated as third quartile values of these parameters. Results: The mean \pm SD of DAP value per procedure was $31.4 \pm 17.1 \mathrm{~Gy} . \mathrm{cm}^{2}$, while corresponding values for fluoroscopy and CINE-acquisition (CINE) were $17.1 \pm 11.2 \mathrm{~Gy} . \mathrm{cm}^{2}$ and $14.4 \pm 8.2 \mathrm{~Gy} . \mathrm{cm}^{2}$, respectively. The estimated mean value of effective dose per procedure was $5.7 \pm 3.1 \mathrm{mSv}$. The projection 40 o $\mathrm{LAO} / 30$ o caudal had the highest DAP rate value during CINE across various projections. Local DRLs were proposed as follows: $39.6 \mathrm{~Gy} . \mathrm{cm}^{2}, 6.9 \mathrm{~min}$, and 679 frames. Conclusion: The mean values of DAP in this study were lower than in previous published literature. Further, deep tube angulation led to increase DAP rates. It is recommended to use minimum tube angulation for avoiding unnecessary radiation exposure.
\end{abstract}

Keywords: Percutaneous coronary interventions, dose-area product, diagnostic reference levels, beam angulation.

\section{INTRODUCTION}

IC procedures play an important role in the diagnosis and treatment of heart diseases. PCI is a non-surgical procedure used to open significantly narrowed or blocked coronary arteries and restore arterial blood flow to the heart tissue. Over the past few decades, the number of IC procedures has been steadily increasing for the following reasons: improvement in X-ray equipment, enhanced cardiologists' clinical skill levels, and advances in stent technologies (1-3). Nowadays, interventional cardiologists perform more complex PCI procedures which were previously impossible or required open surgery. 
IC procedures such as PCI deliver a high radiation dose to the patient, interventional cardiologists, and as well as medical staff $(4,5)$. Although these procedures have great benefits for patients, they often require a long fluoroscopy time and large number of CINE frames especially in complex procedures and repeat $\mathrm{PCI}$ for the same patient. Thus, the risk of stochastic and deterministic radiation effects grows. ED is the most appropriate quantity for estimating stochastic radiation risk and comparing radiation doses across various medical examinations $(1,6,7)$. According to the International Commission on Radiological Protection (ICRP) 119, ED is equal to the sum of the weighted equivalent doses in all tissues and organs of the body ${ }^{(8)}$. In practice, it is difficult to determine ED during IC procedures, as the measured radiation dose in 12 organs is required (1). In literature, ED has been calculated using various methods in cardiac intervention procedures ${ }^{(9-12) . I t}$ is necessary to reduce radiation exposure of patients in $\mathrm{PCI}$ procedures, while still keeping an appropriate image quality.

In IC procedures, the factors that influence the patient radiation exposure are generally classified into three groups: equipment-related, patient-related, and procedure conduct factors (13). One of the most important procedure conduct factors is beam orientation and movement, which is managed by interventional cardiologists. Thus, the cardiologist should understand how beam orientation and movement affect both the patient and their own exposure. Although a wide range of the tube angulations are possible with the current equipment, only a small number of angulations are actually used in IC procedures. Therefore, measuring the radiation dose in different projections is an effective tool for choosing projections with less radiation exposure of patients and medical staff, while concurrently demonstrating all coronary artery segments without foreshortening or overlapping the other structures.

ICRP suggested that the amount of ionizing radiation used to perform medical imaging task should be assessed concerning DRL quantities and they should be easily measured or determined (14). In IC procedures, the assessment of DRLs is difficult, since the patient dose is strongly dependent on the procedure complexity, patient body size, X-ray equipment, and the clinical protocol employed. According to ICRP, local surveys of DRL quantities as part of the quality assurance (QA) program should be performed annually for interventional procedures (14). The current study has been the first patient dose monitoring of PCI procedures in Semnan province. The aims of this study were as follows:

- To measure and assess the radiation doses received using the values recorded by DAP meter and to estimate the patient's effective dose

- To calculate DAP rate in different projections and angles during CINE mode.

- To obtain local DRLs values and eventually compare them with DRLs published in the literatures.

\section{MATERIALS AND METHODS}

\section{Study design}

The study was carried out from April to July 2017 at cardiology department of Semnan Kosar hospital in Iran and included 30 patients (older than 18 years of age) undergoing coronary angioplasty with stenting for single coronary stenosis [Ethical approval code: IR.IUMS.REC 1395.9411581001 date: 21/05/2017].

\section{$X$-ray equipment}

Therapeutic procedures were performed using a Siemens system (Axiom Artis model, Germany) with an over-couch image intensifier detector which was installed in 2008. This unit is capable of performing three fluoroscopy modes including low dose, normal dose, and high dose. It also includes digital CINE modes with 15 and 30 frames per second. In practice, normal dose fluoroscopy (15 pulses per second) and CINE with 15 frames per second are used. In addition, three image intensifier field sizes were available: 25,20 , and $16 \mathrm{~cm}$ in diameter, while a fix field size $(20 \mathrm{~cm})$ was routinely used for all the 
patients. $\mathrm{kV}$ and $\mathrm{mA}$ in the fluoroscopy and CINE were adjusted by Automatic Exposure Control (AEC) system.

\section{Patient positioning}

The patient lay on their back with their head toward C-Arm machine. Projection refers to the path the X-ray beam takes through the body to reach the image receptor. If the image intensifier is perpendicular to the patient and X-ray beam penetrates from patient back to the anterior wall of the chest it is called Posterior-Anterior (PA) projection. This machine takes angles in two different directions. The primary angulation is called left anterior oblique (LAO) or right anterior oblique (RAO) projection where the image intensifier is on the right side of the patient and on the left side of the patient respectively. Secondary angulation refers to caudal or cranial view, where the image intensifier tilts toward the feet and head of the patient respectively. All procedures were performed by two experienced cardiologists. Access to coronary circulation was gained through femoral route without difficulty in any of the patients.

\section{Radiation measurements}

The angiographic unit is equipped with a patient dose measuring system placed in front of the X-ray tube (PTW, Diamentor, Freiberg Germany). This meter consists of a flat ionization chamber measuring DAP which is expressed in $\mathrm{cGy} \cdot \mathrm{cm}^{2}$.The total air kerma at interventional reference point (IRP) used as an indicator for the deterministic effect of radiation on patients (15). The system calculates the values of total air kerma at IRP from DAP and the known position of X-ray tube collimator leaves and displays X-ray units ${ }^{(13)}$ which is expressed in $m G y$.

\section{Data collection}

For each examination, the following patient information was collected: patient ID, age, sex, weight, and the name of cardiologist performing the procedure, as well as a series of technical data. These data included voltage, tube current, and exposure time separately for fluoroscopy and CINE, number of CINE frames, image intensifier field size, additional $\mathrm{Cu}$ filter thickness, source to detector distance (SID), and projection angles. The DAP and ESD values were recorded by the system at every projection during CINE, but these values for fluoroscopy were recorded by the system at the end of each procedure. Note that the equipment output does not provide DAP values at each projection for fluoroscopy; therefore, only DAP rate was calculated for various projections during CINE for each patient. DAP rate was calculated through dividing $\mathrm{DAP}_{\text {cine }}$ of an angulation by CINE time and expressed in terms of cGy.cm ${ }^{2} / \mathrm{sec}$.

\section{Determination of local diagnostic reference levels}

There have been no national DRLs published for PCI procedure in Iran so far. In the present study, local DRLs were determined by calculating the third quartiles values of the DAP, fluoroscopy time, and number of CINE frames (14). These local DRLs values were then compared with the published DRLs.

\section{Patient effective dose}

In this study, for estimating the ED of each patient, the conversion factor was used from Betsou et al.'s study, which was $0.183 \mathrm{mSv}$. Gy${ }^{1} \mathrm{~cm}^{-2}$, converting the DAP value.s to ED, which was estimated using Rando phantom for cardiac intervention procedures ${ }^{(11) .}$

\section{Statistical analysis}

The two samples of continuous variables were compared using statistic Student's t-test, and Shapiro-Wilk test was used to check normal distribution of the variables in both groups. The Mann-Whitney $U$ test was employed for the samples with non-normal distribution. All calculations were performed by using SPSS software Ver.23.0. A P-value of less than 0.05 was considered as statistically significant.

\section{RESULTS}

\section{Patient information description}

According to table 1 , of the 30 patients 
undergoing PCI procedures, 53\% were male, with an average weight of $76.9 \pm 12.4 \mathrm{~kg}$ and age of $64.0 \pm 8.5$ years. All patients were stent implanted, $47 \%$ of whom had lesion in left anterior descending artery (LAD), 23\% in right coronary artery (RCA), $16 \%$ in the left circumflex artery (LCA), and the remainder had lesions in minor arterial branches. The procedures were performed successfully in all patients.

Table 1. Mean \pm SD of DAP and ESD in men and women.

\begin{tabular}{|c|c|c|c|c|c|}
\hline Sex & $\%$ & $\begin{array}{c}\text { Age } \\
\text { (years) }\end{array}$ & $\begin{array}{c}\text { Weight } \\
\text { (kg) }\end{array}$ & $\begin{array}{c}\text { DAP }_{\text {Total }} \\
\text { (Gy.cm }^{2} \text { ) }\end{array}$ & $\begin{array}{c}\text { ESD }_{\text {Total- }} \\
\text { (mGy) }\end{array}$ \\
\hline Men & 53 & $64.0 \pm 8.5$ & $76.9 \pm 12.4$ & $38.2 \pm 19.4$ & $534.3 \pm 301.6$ \\
\hline Women & 47 & $65.6 \pm 9.6$ & $74.1 \pm 9.4$ & $23.7 \pm 10.0$ & $348.3 \pm 166.8$ \\
\hline
\end{tabular}

\section{Patients' received doses}

Table 1 presents the mean values of DAP and ESD for men and women in the present study. Statistical analyses showed that DAP values were significantly different between men and women $(\mathrm{P}=0.03)$. Figure 1 demonstrates the distribution of DAP values in the present study. The mean DAP value per procedures was 31.4 Gy.cm ${ }^{2}$ within the range of 7.0-72.6 Gy.cm ${ }^{2}$. Table 2 report the statistical analysis of DAP and the most important technical parameters individually for fluoroscopy and CINE in the present study. The mean DAP values for fluoroscopy and CINE were $17.1 \pm 11.2 \mathrm{~Gy} . \mathrm{cm}^{2}$ and $14.4 \pm 8.2 \mathrm{~Gy} . \mathrm{cm}^{2}$, respectively. Specifically, $54 \%$ of total DAP was caused by fluoroscopy and the remainder $(46 \%)$ by CINE, while $88 \%$ of exposure total time arose from fluoroscopy and only $12 \%$ was associated with CINE. The $\mathrm{kVp}$ values were approximately similar in both fluoroscopy and CINE, but $\mathrm{mA}$ in CINE was about 5 times higher than in fluoroscopy.

The mean DAP values for various projections of CINE are shown in table 3. Among various projections during CINE, the projection $30^{\circ}$ RAO/ $20^{\circ}$ cranial had the lowest mean DAP (19 cGy. $\mathrm{cm}^{2}$ ) while the projection $30^{\circ}$ LAO/ $50^{\circ}$ caudal had the highest mean DAP (291 cGy.cm²) during the present study. Figure 2 demonstrates the distribution frequency of various projections during CINE. The projection $40^{\circ}$ RAO was the most frequently used projections in patients.

\section{4}

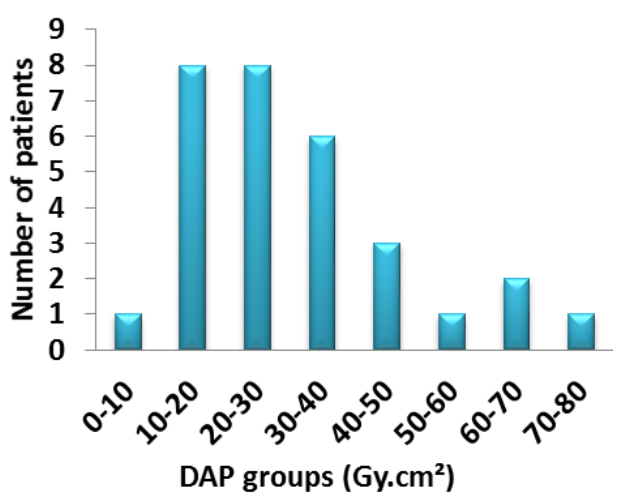

Figure 1. Dose Area Product (DAP) distribution.

Table 2. Radiation exposure parameters for fluoroscopy and cine modes.

\begin{tabular}{|c|c|c|}
\hline Parameter & Mean & SD \\
\hline \multicolumn{3}{|l|}{ Fluoroscopy mode } \\
\hline $\mathrm{kV}$ & 77.67 & 7.57 \\
\hline $\mathrm{mA}$ & 157.38 & 8.94 \\
\hline $\operatorname{DAP}\left(\mathrm{Gy} . \mathrm{cm}^{2}\right)$ & 17.08 & 11.23 \\
\hline Fluoroscopy time(s) & 321.68 & 171.12 \\
\hline Time Fluoro/ time Total & 0.89 & 0.05 \\
\hline $\mathrm{DAP}_{\text {Fluoro }} / \mathrm{DAP} \mathrm{P}_{\text {Total }}$ & 0.54 & 0.12 \\
\hline \multicolumn{3}{|l|}{ CINE mode } \\
\hline kV & 77.78 & 9.20 \\
\hline $\mathrm{mA}$ & 796.25 & 31.67 \\
\hline $\operatorname{DAP}\left(\mathrm{Gy} \cdot \mathrm{cm}^{2}\right)$ & 14.36 & 8.24 \\
\hline CINE time(s) & 37.74 & 11.38 \\
\hline Number of frames & 574 & 170 \\
\hline Time $_{\text {cine }} /$ time Total & 0.11 & 0.05 \\
\hline $\mathrm{DAP}_{\text {Cine }} / \mathrm{DAP}_{\text {Total }}$ & 0.46 & 0.12 \\
\hline
\end{tabular}

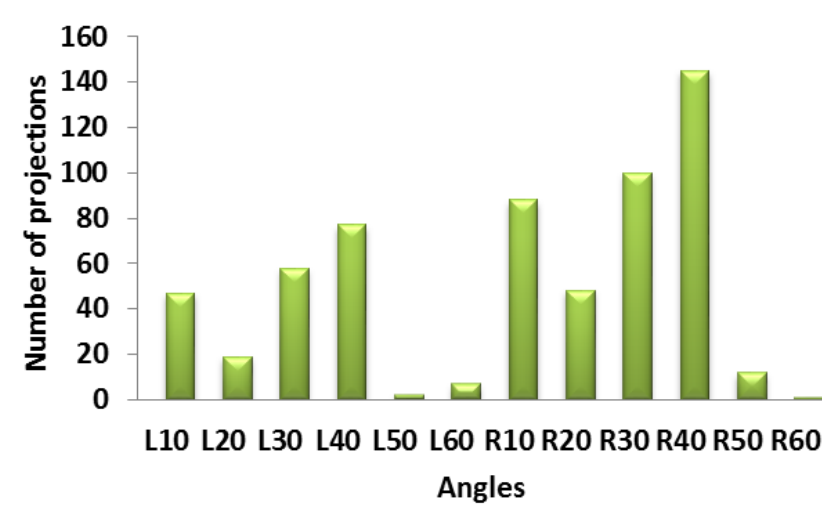

Figure 2.The frequency of projections in different angulation for Left Anterior Oblique (LAO) and Right Anterior Oblique (RAO) projection in the present study.

Int. J. Radiat. Res., Vol. 19 No. 2, April 2021 
Table 3. Mean DAP in units of $\mathrm{cGy} . \mathrm{cm}^{2}$ for various projections during CINE mode.

\begin{tabular}{|c|c|c|c|c|c|c|c|c|c|c|c|c|c|c|}
\hline \multirow{2}{*}{\multicolumn{2}{|c|}{ Degree* }} & & & RAO & & & & PA & & & LAO & & & \\
\hline & & 60 & 50 & 40 & 30 & 20 & 10 & 0 & 10 & 20 & 30 & 40 & 50 & 60 \\
\hline & & $51-60$ & $41-50$ & $31-40$ & $21-30$ & $11-20$ & 1-10 & & $1-10$ & $11-20$ & $21-30$ & $31-40$ & $41-50$ & $51-60$ \\
\hline & & & & & & & & & & & & & & \\
\hline & 50 & & & & & & & & & & & & & \\
\hline & $41-50$ & & 111.62 & 107.03 & 72.64 & 61.99 & \begin{tabular}{|l|}
99.01 \\
\end{tabular} & & 121.17 & & & 286 & & \\
\hline CR & 40 & & & & & & & & & & & & & \\
\hline & $31-40$ & 250 & 91.5 & 73.19 & 57.46 & 41 & 64.99 & & 44.9 & \begin{tabular}{|l|}
171.5 \\
\end{tabular} & & 93 & & \\
\hline & 30 & & & & & & & & & & & & & \\
\hline & $21-30$ & & & 36.92 & 49 & & 36.83 & & 58.05 & 49 & & & & \\
\hline & 20 & & & & & & & & & & & & & \\
\hline & $11-20$ & & & 29 & 19 & & 24 & & 54.67 & 50 & 70.16 & 66.5 & 86 & \\
\hline & 10 & & & & & & & & & & & & & \\
\hline & $1-10$ & & & 22.8 & & 45.25 & & & 22.83 & 47 & 47.51 & 55.73 & 51 & \\
\hline & & & & & & & & & & & & & & \\
\hline PA & 0 & & & & & & & & & & & 44.1 & & \\
\hline & & & & & & & & & & & & & & \\
\hline & 10 & & & & & & & & & & & & & \\
\hline & $1-10$ & & & & 37 & & & & 31.75 & & 67.7 & 50.25 & & 66.25 \\
\hline & 20 & & & & & & & & & & & & & \\
\hline & $11-20$ & & & 48.93 & 32.22 & 62.5 & 116 & & 101 & 28 & & 69 & & 47.25 \\
\hline & 30 & & & & & & & & & & & & & \\
\hline & $21-30$ & & & 69.76 & 54.5 & 57.8 & 45.58 & & 110 & 134.17 & 106.23 & 198 & & \\
\hline CA & 40 & & & & & & & & & & & & & \\
\hline & $31-40$ & & & 98.37 & 57 & 102.39 & \begin{tabular}{|l|}
144.6 \\
\end{tabular} & & 123.62 & 115.58 & 146.74 & 241 & & \\
\hline & 50 & & & & & & & & & & & & & \\
\hline & $41-50$ & & & & & & 158.5 & & & & 291 & & & \\
\hline & & & & & & & & & & & & & & \\
\hline
\end{tabular}

$\mathrm{LAO}=$ Left Anterior Oblique; $\mathrm{RAO}=$ Right Anterior Oblique; $\mathrm{PA}=$ Posterior Anterior; $\mathrm{CR}=$ Cranial; $\mathrm{CA}=$ Caudal

* Degree characters indicate range of typically used tube angulations.

The mean DAP rate was calculated for various projections during CINE, as listed in table 4 . The projection $10^{\circ} \mathrm{RAO} / 20^{\circ}$ cranial had the lowest mean DAP rate $\left(7.7 \mathrm{cGy} . \mathrm{cm}^{2} / \mathrm{sec}\right)$ while $40^{\circ} \mathrm{LAO} / 30^{\circ}$ caudal showed the highest mean DAP rate (123.7 cGy.cm $\left.{ }^{2} / \mathrm{sec}\right)$ in this study. Generally, DAP rate values increased with elevation of the beam angulation in various directions. For example, for $10^{\circ}$ LAO projection, the DAP rate values increased within the range of 11.2-81.4 cGy.cm $2 / \mathrm{sec}$ with the rise of cranial angulation (table 4). Generally, LAO projections had a higher DAP rate compared with RAO projections (mean $\pm \mathrm{SD}, 25.5 \pm 22.3 \mathrm{cGy} . \mathrm{cm}^{2} / \mathrm{sec}$ and $20.3 \pm 10.5 \mathrm{cGy} . \mathrm{cm}^{2} / \mathrm{sec}$, respectively). Further, caudal angulations revealed a higher DAP rate compared with cranial angulations (mean \pm SD, 23.7 $\pm 21.7 \quad$ cGy.cm ${ }^{2} / \mathrm{sec}$ and $21.1 \pm 11.5 \mathrm{cGy}_{\mathrm{cm}} / \mathrm{sec}$, respectively) in the present study.
Effect of the cardiologist skill on patient's dose

All procedures were performed by two invasive intervention cardiologists of catheterization laboratory with the same work experience (8 years of experience), but the number of patients handled by physician $\mathrm{A}$ was three times that of physician B during three consecutive years. The means \pm SD of DAP, fluoroscopy time, CINE time, and number of CINE frames for all procedures performed by each cardiologist are presented in table 5 . The statistical analysis revealed that $\mathrm{DAP}_{\text {Cine, }}$ CINE time, and number of CINE frames were not significantly different between physician $\mathrm{A}$ and B. DAP Fluoro differences in PCI procedures performed by two cardiologist were statistically significant $(\mathrm{P}=0.005)$, which $\mathrm{DAP}_{\text {Fluoro values }}$ recorded for physician $\mathrm{B}$ were approximately twice as large as those for physician A. 
Sancholi et al. / Dose assessment in percutaneous coronary intervention

Table 4. Mean DAP rate in unites $\mathrm{CGy} \cdot \mathrm{cm}^{2} / \mathrm{sec}$ for various projections in CINE mode.

\begin{tabular}{|c|c|c|c|c|c|c|c|c|c|c|c|c|c|c|}
\hline & Degree & & & RAO & & & & PA & & & LAO & & & \\
\hline & & 60 & 50 & 40 & 30 & 20 & 10 & 0 & 10 & 20 & 30 & 40 & 50 & 60 \\
\hline & & $51-60$ & $41-50$ & $31-40$ & $21-30$ & $11-20$ & $1-10$ & & $1-10$ & $11-20$ & $21-30$ & $31-40$ & $41-50$ & \\
\hline & 50 & & & & & & & & & & & & & \\
\hline & $41-50$ & & 38.46 & 63.93 & 32.05 & 51.28 & 56.65 & & 81.43 & & & 105.92 & & \\
\hline CR & 40 & & & & & & & & & & & & & \\
\hline & $31-40$ & 96.15 & 38.13 & 53.53 & 29.29 & 19.87 & 26.92 & & 29.09 & 50.48 & & 42.27 & & \\
\hline & 30 & & & & & & & & & & & & & \\
\hline & $21-30$ & & & 26.96 & 21.04 & & 14.91 & & 22.29 & 18.15 & & & & \\
\hline & 20 & & & & & & & & & & & & & \\
\hline & $11-20$ & & & 32.22 & 8.63 & & 7.74 & & 22.79 & 13.88 & 33.17 & 29.6 & 37.39 & \\
\hline & 10 & & & & & & & & & & & & & \\
\hline & $1-10$ & & & 16.04 & & 22.23 & & & 11.23 & 24.41 & 28.59 & 24.55 & 30 & \\
\hline & & & & & & & & & & & & & & \\
\hline PA & 0 & & & & & & & & & & & 26.52 & & \\
\hline & 10 & & & & & & & & & & & & & \\
\hline & $1-10$ & & & & 21.18 & & & & 19.14 & & 19.35 & 23.75 & & 30.94 \\
\hline & 20 & & & & & & & & & & & & & \\
\hline & $11-20$ & & & 25.38 & 30.38 & 44.24 & 47.84 & & 38.85 & 12.72 & & 32.86 & & 15.46 \\
\hline & 30 & & & & & & & & & & & & & \\
\hline & $21-30$ & & & 39.29 & 28.8 & 26.73 & 24.36 & & 57.14 & 52.92 & 52.72 & 123.75 & & \\
\hline CA & 40 & & & & & & & & & & & & & \\
\hline & $31-40$ & & & 51.4 & 31.66 & 49.63 & 68.97 & & 60.06 & 78.26 & 38.2 & 80.33 & & \\
\hline & 50 & & & & & & & & & & & & & \\
\hline & $41-50$ & & & & & & 73.19 & & & & 121.25 & & & \\
\hline
\end{tabular}

Abbreviations as in Table 4. * Degree characters indicate range of typically used tube angulation.

Table 5. Mean \pm SD of fluoroscopy and CINE parameters for both cardiologists.

\begin{tabular}{|c|c|c|c|c|c|c|}
\hline Cardiologist & $\begin{array}{c}\text { No. of } \\
\text { patients }\end{array}$ & $\begin{array}{c}\text { DAP }_{\text {Cine }} \\
\left(G y . \mathrm{cm}^{2}\right)\end{array}$ & $\begin{array}{l}\text { DAP }_{\text {Fluoro }} \\
\left(G y . \mathrm{cm}^{2}\right)\end{array}$ & $\begin{array}{l}\text { CINE time } \\
\text { (min) }\end{array}$ & $\begin{array}{c}\text { Fluoroscopy } \\
\text { time(min) }\end{array}$ & $\begin{array}{l}\text { No. of } \\
\text { frames }\end{array}$ \\
\hline$A$ & 19 & $13.2 \pm 7.9$ & $12.6 \pm 7.2$ & $0.6 \pm 0.1$ & $4.3 \pm 1.8$ & $554 \pm 153$ \\
\hline B & 11 & $16.3 \pm 8.8$ & $24.7 \pm 13.1$ & $0.6 \pm 0.2$ & $7.3 \pm 3.4$ & $574 \pm 170$ \\
\hline
\end{tabular}

\section{Effective dose}

The mean \pm SD of ED value per procedure was $5.7 \pm 3.1 \mathrm{mSv}$. The ED values were distributed within the range of $1-14 \mathrm{mSv}$.

\section{DISCUSSION}

In recent years, invasive cardiovascular procedures have increased (3,16-18). At present, PCI is carried out in multi-vessel disease, small vessel disease, chronic total occlusion or even complete occlusion in acute myocardial infarction, which leads to longer irradiation time and eventually increased patient radiation exposure. Over the last 3 years, our hospital's catheterization laboratory has performed an average of 1530 PCI procedures per year. In the present study, we recorded data from a total of 30 patients, 16 men and 14 women. DAP and ESD values in men were higher than in women. These differences may be explained by the higher weight of male patients, with the results being in agreement with those obtained by Stratis etal. (19). Note that $46 \%$ of total DAP is attributable to CINE which claims only $12 \%$ of the total exposure time. However, the observed difference between DAP Fluoro and DAP Cine $_{\text {in this }}$ study was not significant. This result may be explained by the fact that $\mathrm{mA}$ of CINE was approximately 5 times higher than fluoroscopy, thereby compensating for the long fluoroscopy

Int. J. Radiat. Res., Vol. 19 No. 1, April 2021 
time. CINE needs a high $\mathrm{mA}$, and as such it generated an image with a high resolution and low noise (13).This finding is contrary to that of Efstathopoulos et al. who found that $66 \%$ of total DAP is attributable to CINE claiming only $13 \%$ of the total irradiation time ${ }^{(10) .}$

The results of this study showed that the projection $40^{\circ} \mathrm{LAO} / 30^{\circ}$ caudal had highest DAP rate values compared to other projections. This finding is in agreement with the study by Tarighatnia et al. (20) who found highest patient's radiation exposure was associated with the projection $50^{\circ} \mathrm{LAO} / 30^{\circ}$ caudal, and it is contrary to the results of the study by Smith et al. (21) who indicated the projection LAO cranial had the highest DAP rate values. The differences in the results of these studies may indicate the fact that patient's radiation exposure is more sensitive to the changes in beam angulation degree, and it reveals this reality that each center should carry out specific measurement and optimization strategy depending on its $\mathrm{X}$-ray machine and physician demand.

Caudal angulations are associated with higher DAP rates compared with cranial angulations, which is consistent with the findings of Agarwal et al. (22). They found that caudal projections had higher air kerma rates compared with cranial projections. It might be due to higher tissue attenuation in caudal angulation. Furthermore, the length of tissue penetration during caudal angulation is larger than that of cranial angulation, whereby the patient dose increases in caudal angulation compared to cranial angulation. This finding is opposite to that of Farajollahi et al. (23) who found the highest DAP rate in cranial angulation. In general, it seems that images generated in caudal angulation have a higher noise level than cranial images do.

With elevation of beam angulation degree, longer parts of the tissue are exposed to X-rays beam, therefore the X-rays trajectory travel a long distance into the patient's body to reach the image intensifier. Then, for compensation, Automatic Brightness Control augments the intensity of X-rays, resulting in elevated patient dose. These results are in agreement with Agrawal's findings (22), who observed progressive increase in the total air kerma rate with elevated beam angulation.

Then, the effect of skill level of cardiologists was investigated on the patient's dose. The lowest DAP values were recorded for cardiologist A, who had a shorter fluoroscopy time. These results may be explained by the fact that high workload intervention has led to increased skill levels for cardiologist A thereby reducing the fluoroscopy time. Surprisingly, generally in previous studies $(16,19,24,25)$, the cardiologist's work experience was expressed in years, but in our study it is expressed in interventions of work load. In our study, the complexity of the intervention was not recorded and therefore was not considered in the analysis.

The results of this study have been compared with the literature findings, as reported in table 6 . The comparison showed that the DAP values, fluoroscopy time, and number of CINE frames were lower than in other studies presented in table 6 . The discrepancy with here could be due to the following reasons: less complexity of the procedures (single stent), use of one X-ray system with the same technical parameters and similar clinical protocols. There has been a wide range of patients' doses for the same type of cardiac intervention procedures, where these variations can be explained by differences in operators' experience, complexity of procedures, clinical protocols, as well as differences in the $\mathrm{X}$-ray system, image intensifier, and catheterization laboratory equipment $(3,18,26,27)$.

In 2008, the SENTINEL consortium investigated patients' dose for IC procedures in nine European centers in order to establish a new reference level (26). Figure 3 compares the European national DRLs and local DRLs in our study. The comparison suggests that the $75^{\text {th }}$ percentiles DAP values (39.6 Gy. $\left.\mathrm{cm}^{2}\right)$, fluoroscopy time (6.9 $\mathrm{min}$ ), and number of CINE frames (679) in our study was lower than European national DRLs. This may be explained by use of a modern X-ray machine and new stent technologies here, as well as the difference in the complexities of the procedures. More studies are required to cover more catheterization laboratories to establish national DRLs in Iran, 
taking into account the complexity of the procedures and patient's size.

Because of the lack of national DRLs for PCI procedures in Iran, ED of the present study were compared with national DRL for coronary CT angiography (CCTA) in Iran. CCTA is a non-invasive examination for assessing coronary arteries (28). The ED (7.2 mSv) in our study was lower than that of national DRL CCTA procedures in Iran (15.1 $\mathrm{mSv}$ ) (28). Out results are in agreement with previous studies (28-31).

The ED was between 1 and $14 \mathrm{mSv}$ for our study. The dose received during PCI is the average 5 times greater than the dose received by annual natural back ground radiation
(3 mSv) (1). According to the "As Low as reasonably achievable "principle, these findings should not reduce our effort for reducing the patient radiation exposure.

\section{Study limitations}

There were some limitations in the present study. Firstly, our conclusions are quantitatively dependent on applied X-ray system and its setting in our center. Secondly, this study had a limited sample size. Moreover, radiation exposure was approximated by DAP; therefore the patient's exact skin dose could only be approximated in the present study.

Table 6. Comparison of dosimetric results in this study and with other researchers' findings.

\begin{tabular}{|c|c|c|c|c|c|c|}
\hline Study & $\begin{array}{c}\text { No. of } \\
\text { cases }\end{array}$ & $\begin{array}{c}\text { DAP(Gy.cm²) } \\
\text { Mean }\end{array}$ & $\begin{array}{c}\text { DAP(Gy.cm²) } \\
\text { SD }\end{array}$ & $\begin{array}{c}\left.\text { DAP(Gy.cm }{ }^{2}\right) \\
\text { 75th percentile }\end{array}$ & \begin{tabular}{|c|}
$\begin{array}{c}\text { Fluoroscopy time } \\
\text { (min) Mean }\end{array}$ \\
\end{tabular} & $\begin{array}{c}\text { No. of frames } \\
\text { Mean }\end{array}$ \\
\hline Bogart et al. ${ }^{(32)}$ & 118 & 81.5 & $\ldots$ & $\ldots$ & $\ldots$ & $\ldots$ \\
\hline Giordano et al. $^{(24)}$ & 40 & 113.5 & $\ldots$ & 137.2 & 16.8 & $\ldots$ \\
\hline Stratis et al. ${ }^{(19)}$ & 101 & 53.8 & 46.7 & 59.99 & 28.7 & 733 \\
\hline Koichi et al. ${ }^{(33)}$ & 172 & 148.6 & $\ldots$ & $\ldots$ & 37.4 & $\ldots$ \\
\hline Nada et al. ${ }^{(34)}$ & 86 & 56.5 & 40.0 & $\ldots$ & 17.6 & $\ldots$ \\
\hline Bouzarjomehri et al..$^{(25)}$ & 84 & 83.2 & 65.6 & 107.4 & 10.0 & 1038 \\
\hline Bahreyni et al. ${ }^{(35)}$ & 28 & 70.9 & $\ldots$ & $\ldots$ & 9.4 & $\ldots$ \\
\hline Khelassi Toutaoui et al. ${ }^{(3)}$ & 22 & 126.0 & 25.1 & 176.0 & 15.0 & $\ldots$ \\
\hline This study & 30 & 31.4 & 17.1 & 39.63 & 5.3 & 574 \\
\hline
\end{tabular}

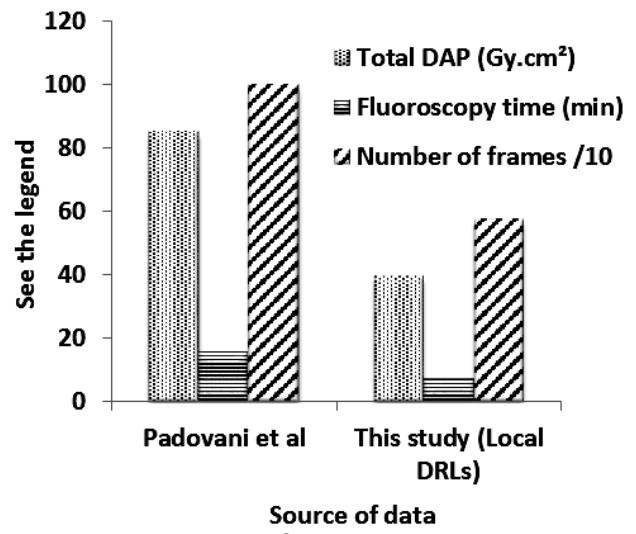

Figure 3. Comparison of local DRLs in our study with European national DRLs.

\section{CONCLUSION}

The results of this investigation revealed the impact of beam angulation in various directions on DAP rate. According to our findings, use of the minimum angulation as much as possible is suggested, while keeping a good view of coronary arteries. We suggest educational programs for catheterization laboratories staff in order to obtain the optimal image quality with minimum level of exposure for both patients and personnel.

\section{ACKNOWLEDGMENTS}

The authors would like to thank the cardiologists, nurses and radiology technologists of kosar hospital for their cooperation and assistance during the study. The authors would also like to thank Shima Amine for their precious assistance throughout the study. This work was supported by Radiation Biology Research Center 
of Iran University of Medical sciences.

\section{Conflicts of interest: Declared none.}

\section{REFERENCES}

1. Tsapaki V (2010) Radiation dose in interventional cardiology. Imaging in Medicine, 2(3): 303-312.

2. Nikam N, Steinberg TB, Steinberg DH (2014) Advances in stent technologies and their effect on clinical efficacy and safety. Medical Devices: Evidence and Research (Auckland, NZ), 7: 165-178.

3. Khelassi-Toutaoui N, Toutaoui A, Merad A, Sakhri-Brahimi Z, Baggoura B, Mansouri B (2016) Assessment of radiation protection of patients and staff in interventional procedures in four Algerian hospitals. Radiation Protection Dosimetry, 168(1): 55-60.

4. Larrazet F, Dibie A, Philippe F, Palau R, Klausz R, Laborde F (2003) Factors influencing fluoroscopy time and dosearea product values during ad hoc one-vessel percutaneous coronary angioplasty. The British Journal of Radiology, 76(907): 473-7.

5. Szumska A, Kopeć R, Budzanowski M(2016) Occupational doses of medical staff and their relation to patient exposure incurred in coronary angiography and intervention. Radiation Measurements, 84: 34-40.

6. Maghbool M and Hosseini M (2019) An assessment of radiation exposure doses in patients undergoing primary percutaneous coronary intervention based on angiographic records. Radiation Protection Dosimetry, 183(4): 47582.

7. Bouzarjomehri F and Tsapaki V (2010) Evaluation of cancer risk of the patients undergoing coronary angiography in Yazd, Iran. Int J Radiat Res, 8(3): 161-167.

8. Ann ICRP (2012) Compendium of Dose Coefficients based on ICRP Publication 60: ICRP Publication 119, 41(Suppl).

9. Molyvda-Athanasopoulou E, Karlatira M, GotzamaniPsarrakou A, Koulouris C, Siountas A (2011) Radiation exposure to patients and radiologists during interventional procedures. Radiation Protection Dosimetry, 147(1-2): 8690.

10. Efstathopoulos EP, Karvouni E, Kottou S, Tzanalaridou E, Korovesis S, Giazitzoglou E, et al. (2004) Patient dosimetry during coronary interventions: a comprehensive analysis. American Heart Journal, 147(3): 468-475.

11. Betsou S, Efstathopoulos E, Katritsis D, Faulkner K, Panayiotakis $G$ (1998) Patient radiation doses during cardiac catheterization procedures. The British Journal of Radiology, 71(846): 634-639.

12. Schultz F, Zoetelief J(2005) Dose conversion coefficients for interventional procedures. Radiation Protection Dosimetry, 117(1-3): 225-230.

13. Hirshfeld JW, Balter S, Brinker JA, Kern MJ, Klein LW, Lindsay BD, et al. (2004) ACCF/AHA/HRS/SCAl clinical competence statement on physician knowledge to optimize pa-

Int. J. Radiat. Res., Vol. 19 No. 2, April 2021 tient safety and image quality in fluoroscopically guided invasive cardiovascular procedures: a report of the American College of Cardiology Foundation/American Heart Association/American College of Physicians Task Force on Clinical Competence and Training. Journal of the American College of Cardiology, 44(11): 2259-2282.

14. Vañó E, Miller D, Martin C, Rehani M, Kang K, Rosenstein $M$, et al. (2017) Diagnostic reference levels in medical imaging. Annals of the ICRP. ICRP Publication 135, 46(1): 1 $-144$.

15. Seiffert M, Ojeda F, Müllerleile K, Zengin E, Sinning C, Waldeyer C, et al. (2015) Reducing radiation exposure during invasive coronary angiography and percutaneous coronary interventions implementing a simple four-step protocol. Clinical Research in Cardiology, 104(6): 500-506.

16. Tsapaki V, Kottou S, Vano E, Faulkner K, Giannouleas J, Padovani $R$, et al. (2003) Patient dose values in a dedicated Greek cardiac centre. The British Journal of Radiology, 76(910): 726-730.

17. Durán A, Hian SK, Miller DL, Le Heron J, Padovani R, Vano E (2013) Recommendations for occupational radiation protection in interventional cardiology. Catheterization and Cardiovascular Interventions, 82(1): 29-42.

18. Pantos I, Patatoukas G, Katritsis DG, Efstathopoulos E (2009) Patient radiation doses in interventional cardiology procedures. Current Cardiology Reviews, 5(1): 1-11.

19. Stratis Al, Anthopoulos PL, Gavaliatsis IP, Ifantis GP, Salahas Al, Antonellis IP, et al. (2009) Patient dose in cardiac radiology. Hellenic J Cardiol, 50(1): 17-25.

20. Tarighatnia A, Mohammadalian A, Ghojazade M, Pourafkari L, Farajollahi A (2017) Beam projections and radiation exposure in transradial and transfemoral approaches during coronary angiography. Anatolian Journal of Cardiology, 18(4): 298-303.

21. Smith IR, Cameron J, Mengersen KL, Rivers JT (2012) Evaluation of coronary angiographic projections to balance the clinical yield with the radiation risk. The British Journal of Radiology, 85(1017): 722-728.

22. Agarwal S, Parashar A, Bajaj NS, Khan I, Ahmad I, Heupler FA, et al. (2014) Relationship of beam angulation and radiation exposure in the cardiac catheterization laboratory. JACC: Cardiovascular Interventions, 7(5):558-566.

23. Farajollahi A, Rahimi A, Shal EK, Ghaffari S, Ghojazadeh M, Tajlil A, et al. (2014) Patient's radiation exposure in coronary angiography and angioplasty: the impact of different projections. Journal of Cardiovascular and Thoracic Research, 6(4): 247-252.

24. Giordano C, D'Ercole L, Gobbi R, Bocchiola M, Passerini F (2010) Coronary angiography and percutaneous transluminal coronary angioplasty procedures: Evaluation of patients' maximum skin dose using Gafchromic films and a comparison of local levels with reference levels proposed in the literature. Physica Medica, 26(4): 224-232.

25. Bouzarjomehri F and Tsapaki V (2009) Patient dose values during interventional cardiology examinations in Yazd hospital, Iran. Int J Radiat Res, 6(4): 167-172.

26. Padovani R, Vano E, Trianni A, Bokou C, Bosmans H, Bor D, et al. (2008) Reference levels at European level for cardiac 


\section{Sancholi et al. / Dose assessment in percutaneous coronary intervention}

interventional procedures. Radiation Protection Dosimetry, 129(1-3): 104-107.

27. Neofotistou V, Vano E, Padovani R, Kotre J, Dowling A, Toivonen $\mathrm{M}$, et al. (2003) Preliminary reference levels in interventional cardiology. European Radiology, 13(10): 2259-2263.

28. Hosseini Nasab SMB, Shabestani-Monfared A, Deevband MR, Paydar R, Nabahati M (2017) Estimation of cardiac CT angiography radiation dose toward the establishment of national diagnostic reference level for CCTA in Iran. Radiation Protection Dosimetry, 174(4): 551-557.

29. Dill T, Deetjen A, Ekinci O, Möllmann S, Conradi G, Kluge A, et al. (2008) Radiation dose exposure in multislice computed tomography of the coronaries in comparison with conventional coronary angiography. International Journal of Cardiology, 124(3): 307-311.

30. Coles DR, Smail MA, Negus IS, Wilde P, Oberhoff M, Karsch $\mathrm{KR}$, et al. (2006) Comparison of radiation doses from multislice computed tomography coronary angiography and conventional diagnostic angiography. Journal of the American College of Cardiology, 47(9): 1840-1845.

31. Jabara R, Chronos N, Klein L, Eisenberg S, Allen R, Bradford $S$, et al. (2007) Comparison of multidetector 64-slice com- puted tomographic angiography to coronary angiography to assess the patency of coronary artery bypass grafts. The American Journal of Cardiology, 99(11): 1529-1534.

32. Bogaert E, Bacher K, Lemmens K, Carlier M, Desmet W, De Wagter $X$, et al. (2009) A large-scale multicentre study of patient skin doses in interventional cardiology: dose-area product action levels and dose reference levels. The British Journal of Radiology, 82(976): 303-312.

33. Chida K, Saito H, Otani H, Kohzuki M, Takahashi S, Yamada $S$, et al. (2006) Relationship between fluoroscopic time, dose-area product, body weight, and maximum radiation skin dose in cardiac interventional procedures. American Journal of Roentgenology, 186(3): 774-778.

34. Ahmed NA, Ibraheem S, Habbani F (2013) Patient doses in interventional cardiology procedures in Sudan. Radiation Protection Dosimetry, 153(4): 425-430.

35. Bahreyni Toossi MT, Baradaran SF, Gholoobi A, Nademi H (2013) Evaluation of Maximum Patient Skin Dose Arising from Interventional Cardiology Using Thermoluminescence Dosimeter in Mashhad, Iran. Iranian Journal of Medical Physics, 10(2): 87-94. 